\title{
Modulation of environmental conditions on the significant difference in the super cyclone formation rate during the pre-and post-monsoon seasons over the Bay of Bengal
}

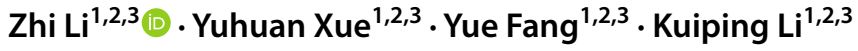

Received: 15 September 2020 / Accepted: 8 June 2021 / Published online: 18 June 2021

(c) The Author(s) 2021

\begin{abstract}
Unlike other tropical ocean basins, the Bay of Bengal (BoB) has two tropical cyclone (TC) seasons: a pre-monsoon season (Pre-MS) and a post-monsoon season (Post-MS). More interestingly, during the period from 1981 to 2016, the global maximum and minimum formation rates of super cyclones (SCs, categories 4 and 5) occurred in the Pre-MS and Post-MS, respectively, in the BoB. Methods including Butterworth filter, box difference index analysis and quantitative diagnosis were utilized herein to detect what and how background environmental factors cause significantly different SC formation rates between the Pre- and Post-MS. Diagnosis results revealed that the vertical temperature difference (VTD) mainly determines whether TCs can develop into SCs during the Post-MS, similar to Pre-MS. It's in agreement with previous studies demonstrating that the VTD is controlled by the low-level temperature during the Post-MS but is determined by the upper-level temperature during the Pre-MS. The results also revealed that the background sea surface temperature is much higher in the Pre-MS than in the Post-MS and forces higher $1000 \mathrm{hPa}$-level air temperature. Additionally, there is higher saturated specific humidity $\left(\mathrm{q}_{\mathrm{s}}\right)$ due to the higher temperature in the Pre-MS. The differences in the bottom-level temperature and $\mathrm{q}_{\mathrm{s}}$ cooperate to predominantly contribute to the significant difference in $\mathrm{V}_{\text {pot }}{ }^{2}$, which could denote the maximum potential intensity of $\mathrm{TC}$, eventually leading to the remarkably different SC formation rates between the Pre- and Post-MS in the BoB.
\end{abstract}

\section{Introduction}

Tropical cyclones (TCs) are severe weather systems and one of the most frequent natural disasters, and they are likely to strike the coastal regions of tropical oceans (Emanuel 2003; Pielke et al. 2008; Blake et al. 2011; Li et al. 2013). The ocean conditions over the Bay of Bengal (BoB), which is located in the Indo-Pacific warm pool, are conducive to TC genesis, but the BoB TC frequency accounts for only approximately $4 \%$ of global TCs. Although fewer TCs form over the BoB than over other tropical basins, such as the

Zhi Li

lizhi@fio.org.cn

1 Center for Ocean and Climate Research, First Institute of Oceanography, MNR, Qingdao 266061, China

2 Laboratory for Regional Oceanography and Numerical Modeling, Pilot National Laboratory for Marine Science and Technology, Qingdao 266237, China

3 Shandong Key Laboratory of Marine Science and Numerical Modeling, Qingdao 266061, China
Northwest Pacific (NWP), the Northeast Pacific (NEP), the North Atlantic (NA), the South Pacific (SP), and the South Indian Ocean (SIO), the BoB rim incurs approximately $80 \%$ of TC-induced fatalities experienced worldwide (Needham et al. 2015). In particular, approximate three-quarters of the top 35 deadliest TCs worldwide have taken place in the BoB; this predilection is because of the distribution of densely populated, low-lying areas and the very shallow continent shelf, which amplifies storm surges (Jakobsen et al. 2006). For example, TC Nargis (Webster 2008; Kikuchi et al. 2009; Lin et al. 2009; McPhaden et al. 2009; Yanase et al. 2010), which struck the southern coast of Myanmar on 2 May 2008, caused the worst natural disaster in the recorded history of Myanmar. Such tremendous socioeconomic implications call for a better understanding of the mechanisms responsible for intensifying TCs over the BoB to improve TC intensity operational forecasts and projected changes in a warming world.

Unlike those over the NWP, NEP, NA, SP and SIO, TCs over the BoB have an annual cycle with a distinctly bimodal distribution, wherein TCs occur mostly during the premonsoon season (Pre-MS, April-May) and post-monsoon 
season (Post-MS, October-November) (Yanase et al. 2012; Li et al. 2013; Akter et al. 2014). Furthermore, the TCs are significantly more frequent in the Post-MS than the Pre-MS. However, the super cyclone (SC, category 4 and 5 TCs) formation rates (rates of SC frequency to total TC frequency) in the BoB are very different between the Pre-MS and PostMS. More interestingly, the BoB SC formation rates in the Pre- and Post-MS separately are the maximum and minimum $\mathrm{SC}$ formation rate globally.

The cyclone over the BoB has always been an area of interest in cyclone research because of its unique bimodal features. Previous papers have reported that the vertical wind shear (VWS) between the 850 and $200 \mathrm{hPa}$ levels becomes strong during the summer monsoon and plays a critical role in destroying the warm core and even inhibiting TC genesis over the BoB (Gray 1968; Camargo et al. 2007; Evan and Camargo 2011; Yanase et al. 2012). Li et al. (2013), by the quantitative diagnosis based on TC genesis potential index (GPI) proposed by Emanuel and Nolan (2004), further presented the VWS needed to work with absolute vorticity and potential intensity (PI) to counteract the effect of mid-level relative humidity $(\mathrm{RH})$ on $\mathrm{TC}$ formation and ultimately to inhibit TC activities during the prevailing monsoon period.

In addition, the TC frequency is much lower in the PreMS than the Post-MS. Some studies have focused on the asymmetry of the peaks in the bimodal distribution. Akter and Tsuboki (2014) thought the convective inhibition and monsoon trough locations in combination brought about the asymmetric peaks in the Pre- and Post-MS. According to the GPI of TC (Emanuel and Nolan 2004), the asymmetry of the TC frequency was attributed to the mid-level RH difference between the Pre- and Post-MS (Li et al. 2013).

Similar to TCs, SCs over the BoB also have a bimodal distribution, but they are more frequent during the Pre-MS than the Post-MS. Furthermore, the results of some papers focused on the formation of SCs in this region during the Pre-MS suggest that the formation of SCs in the North Indian Ocean is mainly attributable to the weak easterly vertical shear (Rao et al. 2008; Kotal et al. 2008). Li et al. (2019a) illustrated two conditions to determine whether BoB TCs are able to develop into SCs during the Pre-MS at an intraseasonal timescale: one is the distance between the TC and northward-propagating Intraseasonal Oscillation (ISO), and the other is the intensity of the ISO. When the distance between the TC and ISO is shorter and the ISO is stronger, the ISO can increase the temperature difference between the lower and upper levels around TC centers through the overshooting effect, and eventually propel the TC intensity towards becoming an SC ( $\mathrm{Li}$ et al. 2019a).

Some studies have focused on the formation of SCs over the BoB during the Pre-MS (Kotal et al. 2009a; Li et al. 2016, 2019a), but few studies have attempted to explain why the SC formation rate is far lower in the Post-MS than the Pre-MS.
Balaguru et al. (2012) indicated that the ocean barrier layer is able to prevent a sharp reduction of sea surface temperature (SST) by strengthening the stratification to weaken storminduced Ekman pumping when cyclones pass over barrierlayer regions, which is conductive to enhancement of the cyclone intensity. Unlike the Post-MS, the Pre-MS in the BoB exhibits an obvious shoaling and thin barrier layer (Thadathil et al. 2007; Vissa et al. 2013; Yesubabu et al. 2020); therefore, the barrier layer may not explain why the Pre-MS is more prone to SC occurrence than the Post-MS. Neetu et al. (2019) postulated that BoB TCs are stronger before compared with after the monsoon due to favorable large-scale background conditions; however, there is a lack of quantitative diagnostic proof to illuminate the inner physical processes that determine the difference in the SC formation rate between the Pre- and Post-MS. Considering the current situation, a more specific analysis is needed to explain what and how environmental conditions and physical processes modulate the significantly different SC formation rate between the Pre- and Post-MS in the BoB.

Therefore, this paper attempts to improve our understanding of this issue. The data and methodology are described in Sect. 2, and the results are presented in Sects. 3 and 4. Finally, we summarize the results in Sect. 5 .

\section{Data and methods}

Previous research on TCs has demonstrated that environmental factors related to TC genesis and development mainly include outgoing longwave radiation (OLR), SST, sea surface temperature anomaly (SSTA), air temperature (T), wind, RH, and specific humidity (SH) and vertical motion ( $\omega$ ) (Gray 1968, 1979; Emanuel and Nolan 2004; Kotal et al. 2009b; Zhang et al. 2016). Hence, the primary datasets used in this study included the (1) International Best Track Archive for Climate Stewardship (IBTrACS) downloaded from the Joint Typhoon Warning Center (JTWC), (2) daily OLR data from the National Oceanic and Atmospheric Administration (NOAA), (3) daily SST and SSTA data from NOAA high-resolution analysis datasets, and (4) daily T, wind, $\omega, \mathrm{RH}$ and SH data from the National Centers for Environmental Prediction (NCEP)-National Center for Atmospheric Research (NCAR) reanalysis. Excluding the SST and SSTA data, which have a $0.25^{\circ} \times 0.25^{\circ}$ latitude-longitude grid, all the datasets have a horizontal resolution of $2.5^{\circ}$ latitude by $2.5^{\circ}$ longitude. According to Bister and Emanuel (2002), the maximum PI of a TC can be written as follows:

$$
\begin{aligned}
& V_{p o t}^{2}=C_{p} \cdot \frac{C_{k}}{C_{D}} \cdot T_{v d} \cdot T_{r d} \cdot T_{e d} \\
& T_{v d}=T_{s}-T_{o}
\end{aligned}
$$


$T_{v r}=T_{s} / T_{o}$

$T_{e d}=\ln \theta_{e}^{*}-\ln \theta_{e}$

where $V_{p o t}$ is the PI, $C_{p}$ is the heat capacity at constant pressure, $C_{k}$ is the exchange coefficient for enthalpy, $C_{D}$ is the drag coefficient, $T_{s}$ is the surface temperature, $T_{o}$ is the mean outflow temperature, $\theta_{e}{ }^{*}$ is the saturation equivalent potential temperature at the ocean surface, and $\theta_{e}$ is the boundary layer equivalent potential temperature.

We adopted a total differentiation method similar to that developed by Li et al. (2013) to examine the relative contribution of each term. Then, the contribution of each term to the difference in the $\mathrm{V}_{\text {pot }}{ }^{2}$ term between the Pre- and PostMS could be written as follows:

$\Delta V_{p o t}^{2}=\alpha_{1} \cdot \Delta T_{v d}+\alpha_{2} \cdot \Delta T_{v r}+\alpha_{3} \cdot \Delta T_{e d}$

$\Delta V_{\text {pot }}^{2}=V_{\text {potpre }}^{2}-V_{\text {potpost }}^{2}$

$\Delta T_{v d}=T_{v d p r e}-T_{v d p o s t}$

$\Delta T_{v r}=T_{v r p r e}-T_{v r p o s t}$

$\Delta T_{\text {ed }}=T_{\text {ed pre }}-T_{\text {ed post }}$

Herein, an approximation has been made in deriving Eq. (2) by assuming that $\alpha_{1}, \alpha_{2}$ and $\alpha_{3}$ are constant coefficients such that

$\left\{\begin{array}{l}\alpha_{1}=T_{\text {vrpost }} \cdot T_{\text {edpost }} \\ \alpha_{2}=T_{\text {vdpost }} \cdot T_{\text {edpost }} \\ \alpha_{3}=T_{\text {vdpost }} \cdot T_{\text {vrpost }}\end{array}\right.$

where the subscripts 'pre' and 'post' denote Pre-MS and Post-MS, respectively.

Moreover, the Butterworth filter (Hamming 1989) was utilized to derive 15-day low-pass components as the background field. The box difference index (BDI) (Fu et al. 2012; Peng et al. 2012; Li et al. 2019a) and T-test methods were used herein to quantitatively contrast the difference in environmental factors associated with TC development between the Pre- and Post-MS to ascertain the substantially different factors and their significance level. The BDI is defined as follows:

$B D I=\frac{\text { Mean }_{\text {pre }}-\text { Mean }_{\text {post }}}{\sigma_{\text {pre }}+\sigma_{\text {post }}}$

where Mean denotes the mean of all samples for one particular variable and $\sigma$ denotes the standard deviation. The subscripts 'pre' and 'post' represent the Pre- and Post-MS, respectively.

Based on the 15-day low-pass background data, a composite analysis was conducted to detect the reason for SC formation during Post-MS and to reveal the predominant physical processes which are responsible for the difference in the SC formation rate between the Pre- and Post-MS in the BoB.

\section{Environmental conditions for SC and TC formation}

The climatologic annual cycle of BoB TCs features a distinctive bimodal pattern, where the peaks correspond to Preand Post-MS. A total of 86 cyclones occurred during the Pre- and Post-MS from 1981 to 2016 over the BoB. Among them, 19 TCs, including 7 SCs and 12 regular-intensity TCs, occurred in the Pre-MS. The remaining 67 TCs, including 7 SCs and 60 regular-intensity TCs, occurred in the Post-MS. The statistical results showed the TC frequency in the PostMS was approximately 4 times greater than in the Pre-MS, but the SC formation rate in the Post-MS was approximately one quarter of that in the Pre-MS, reflecting stark contrasts between the two periods (Table 1).

\subsection{Impact factors for TC intensity during the Pre-MS}

During the Pre-MS, the formation of SCs originates from intraseasonal and interannual timescale modulations. At the intraseasonal time scale, the strong intensity of the first-branch northward-propagating Intraseasonal Oscillation (FNISO) and the relatively short distance between the TC centers and FNISO centers work together to effectively reduce the upper-level $\mathrm{T}$ by the overshooting effect and subsequently intensify the vertical temperature difference

Table 1 SC formation rate during the TC season over the past 36 years (1981-2016) for each ocean basin

\begin{tabular}{llllllll}
\hline Basin TC season & BoB (4-5) & BoB (10-11) & WNP (7-10) & ENP (7-10) & NATL (7-10) & SIO (1-4) & SP (1-4) \\
\hline SC & 7 & 7 & 179 & 92 & 52 & 114 & 23 \\
TC & 19 & 67 & 731 & 24.5 & 16.2 & 430 & 706 \\
SC rate $(\%)$ & 36.8 & 10.4 & & 12.1 & 16.1 & 17.7 \\
\hline
\end{tabular}


(VTD). VTD plays a critical thermodynamic role in modulating the TC PI during the Pre-MS. A larger VTD tends to strengthen the TC PI, and vice versa ( $\mathrm{Li}$ et al. 2019a).

Moreover, at the interannual scale, the upper-level $\mathrm{T}$ anomaly is consistent with the anomalous SST during the Pre-MS in the tropical Indian Ocean. The composite upperlevel T during SCs is lower than that during TCs, and the VTD is significantly larger in SCs than in TCs. This VTD variation exerts a similar effect on the PI of TCs. All of these conditions at intraseasonal and interannual timescales cooperate to predominantly determine whether some TCs develop into SCs (Li et al. 2019a).

\subsection{BDI analysis for the Post-MS}

In the past 36 years (1981-2016), the worldwide maximum SC formation rate in the Pre-MS has been completely antithetical to the globally minimum SC formation rate that occurs in the Post-MS in the BoB. To understand the environmental factors and physical processes that cause this sharp contrast in SC formation rate between the Pre-MS and Post-MS, we next investigate the dominant factors impacting TC intensity during the Post-MS.

Here, the BDI and T-test were utilized to quantitatively select the key environmental factors that were significantly different between the SC and TC groups. The results are listed in Tables 2, 3 .

This analysis focuses on the period from TC genesis to its climax. During the Post-MS, the ISO (20-100-day bandpass filtered signal) intensity in the SC group was similar to that in the TC group. Therefore, such a miniscule difference in

Table 2 BDI and significance level of the factors between the SC and TC groups during the Post-MS

\begin{tabular}{llllll}
\hline $\begin{array}{l}\text { SC-TC } \\
10^{\circ} \times 10^{\circ}\end{array}$ & OLR of ISO & $\begin{array}{l}\text { ISO OLR } \\
\text { over SC/ } \\
\text { TC centers' } \\
\text { region }\end{array}$ & VWS & SST & PI \\
\hline BDI & 0.04 & 0.13 & -0.16 & 0.22 & 0.19 \\
Significance & No & No & No & $>95 \%$ & $>95 \%$
\end{tabular}

ISO is 20-100-day bandpass-filtered, while the other factors are 15-day low-pass-filtered the ISO intensity should not greatly affect the formation of SCs during the Post-MS (Table 2).

Then, a 15-day low-pass filter was applied with the annual cycle removed to eliminate the synoptic-scale impact representing the background signal. The BDI and T-test analysis of background environmental factors showed that the SST was remarkably different between the SC and TC groups at a significance level greater than $95 \%$, signifying that SST should play a leading role in TC intensity development during the Post-MS. Though VWS was weaker in the SC group than the TC group, we believe that the positive contribution of VWS to the TC intensity difference might be limited since the difference in VWS was very small and not significant (Table 2). Similar to VWS, the insignificant ISO difference rarely contributed to the TC intensity difference between SC and TC group (Table 2).

Compared with the other atmospheric factors, such as vorticity, RH and $\omega$, the low-level SH and T at almost all levels had larger BDI values and greater significant differences between the SC and TC groups. T was significantly different between SC and TC groups at all levels except the $200 \mathrm{hPa}$ level (Table 3). Although SH showed obvious differences between the SC and TC groups in the boundary layer, $\mathrm{RH}$ was similar because the higher $\mathrm{T}$ led to a larger value of saturated $\mathrm{SH}\left(\mathrm{q}_{\mathrm{s}}\right)$, and $\mathrm{RH}$ is the ratio of actual $\mathrm{SH}$ to $\mathrm{q}_{\mathrm{s}}$. A similar RH might imply that the contribution of the water vapor phase transition to TC genesis and development was also similar between the SC and TC groups. Fully considering the differences in $\mathrm{SH}, \mathrm{RH}$, and $\mathrm{T}$ between the $\mathrm{SC}$ and $\mathrm{TC}$ groups and their BDI values (Table 3), it could be deduced that $\mathrm{T}$ was the most dominant influencing factor.

\subsubsection{Composite analysis for the Post-MS}

Especially in the low-level atmosphere, the $\mathrm{T}$ difference between the SC and TC groups was highly noticeable, and its significance level easily exceeded $95 \%$. The composite of the low-tropospheric $\mathrm{T}$ for SC cases was warmer than that for TC cases, but the upper-tropospheric ( $200 \mathrm{hPa}$ ) average $\mathrm{T}$ field was very similar and even colder in the SC group than the TC group (Fig. 1). However, the composite RH of the $\mathrm{SC}$ group was similar to the TC group; this also suggested
Table 3 BDI of each $10^{\circ} \times 10^{\circ}$ box around the SC and TC centers at multiple atmospheric levels during the Post-MS

\begin{tabular}{lcccccccccc}
\hline SC-TC & 1000 & 925 & 850 & 700 & 600 & 500 & 400 & 300 & 250 & 200 \\
\hline Vor & 0.15 & & -0.11 & $-0.23^{*}$ & & $-0.20^{*}$ & -0.10 & -0.00 & 0.07 & 0.17 \\
RH & -0.09 & & 0.15 & 0.19 & & -0.12 & -0.05 & -0.05 & & \\
SH & $0.30^{*}$ & $0.29^{*}$ & $0.30^{*}$ & 0.01 & 0.00 & -0.07 & -0.09 & -0.14 & & \\
$\omega$ & 0.08 & 0.12 & 0.12 & 0.20 & 0.20 & 0.17 & 0.12 & 0.12 & 0.10 & 0.05 \\
T & $0.56^{*}$ & $0.59^{*}$ & $0.40^{*}$ & $0.26^{*}$ & $0.34^{*}$ & $0.36^{*}$ & $0.49^{*}$ & $0.43^{*}$ & $0.31^{*}$ & 0.12 \\
\hline
\end{tabular}

*Means the significance level is $>95 \%$. The blank means no data there 
that the low-level $\mathrm{T}$ might be the leading factor affecting the TC intensity.

In the PI formula of Bister and Emanuel (2002), the T difference between 1000 and $200 \mathrm{hPa}$, i.e., the VTD, is regarded as a key factor that directly affects the PI of TC. A greater VTD between the lower and upper troposphere reflects increasing atmospheric instability and then enhancing TC intensity. Thus, we further analyze the $\mathrm{T}$ at both lower and upper levels.

The composites of the 15-day low-pass-filtered $\mathrm{T}$ for the SC and TC cases were $0.28^{\circ} \mathrm{C}$ and $-0.09^{\circ} \mathrm{C}$, respectively, at the $1000 \mathrm{hPa}$ level and $0.29^{\circ} \mathrm{C}$ and $0.38^{\circ} \mathrm{C}$, respectively, at the $200 \mathrm{hPa}$ level (Fig. 2). The composites of the VTD for the SC and TC cases were approximately $-0.01{ }^{\circ} \mathrm{C}$ and $-0.47{ }^{\circ} \mathrm{C}$, respectively. This obvious disparity in the VTD induced a remarkable difference in the PI between the SC and TC groups with a significance level above $95 \%$ and further modulated whether TCs could develop into SCs. Although the dominant controlling factor on SC formation in both the Pre-MS and Post-MS was the VTD, the processes by which the VTD was modulated in the Pre- and Post-MS were entirely different. Li et al. (2019a) concluded that the VTD between the SC and TC groups mainly originates from the upper-level $\mathrm{T}$ difference during the Pre-MS (see their Fig. 5). However, we have shown that the remarkable difference in the VTD derives from the low-level $\mathrm{T}$ difference during the PostMS (Fig. 2).

Moreover, detailed analysis revealed that the composite SST for SC cases was much warmer than for TC cases, and their difference exceeded the $95 \%$ significance level; additionally, the low-level T difference fit well with the SST difference between the SC and TC groups (Fig. 3). Therefore, the low-level $\mathrm{T}$ difference between the SC and TC groups might be attributable to the SST difference forcing.

In summary, in the Post-MS, the low-level T forced by SST was higher in the SC group than the TC group. However, the $200 \mathrm{hPa}$-level $\mathrm{T}$ was not significantly different between the two groups. Therefore, the VTD between the $\mathrm{SC}$ and TC groups was governed mainly by the low-level T difference. A relatively large (small) VTD induced a relatively strong (weak) PI in the SC (TC) group. Accordingly, we can better understand $\mathrm{SC}$ formation conditions during the Post-MS in the BoB.
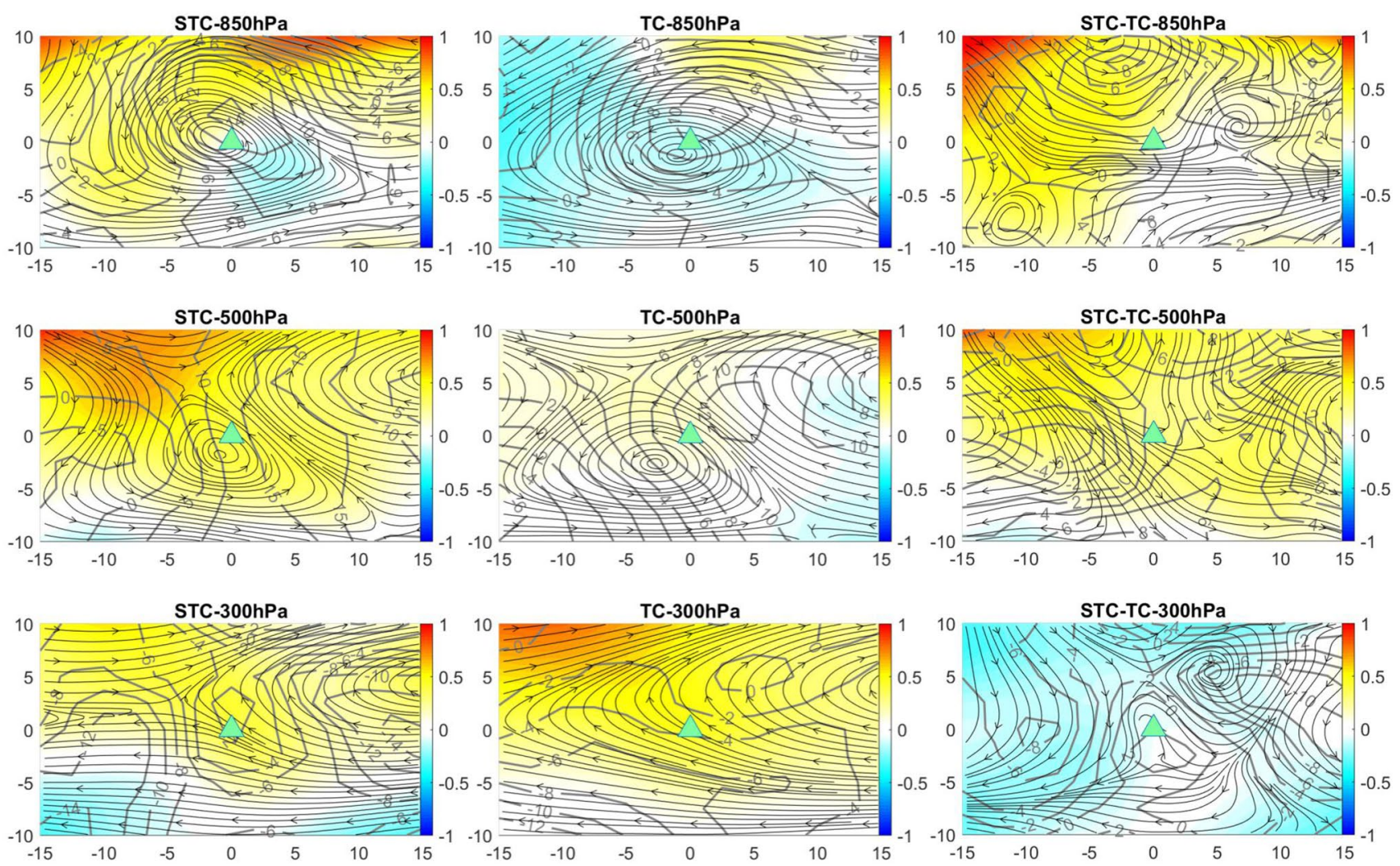

Fig. 1 Composites of the air temperature (T, unit: $\left.{ }^{\circ} \mathrm{C}\right)$, relative humidity (RH, unit: \%), and wind (unit: $\mathrm{ms}^{-1}$ ) around the SC centers (the left panel), TC centers (the middle panel) and their difference (the right panel) on a timescale greater than 15 days. The shading is the filtered $\mathrm{T}$, the gray contour line is the filtered $\mathrm{RH}$, the streamline is the filtered wind, and the green triangle is the cyclone center. Note that in the bottom panels, the contour lines and streamlines are the $300 \mathrm{hPa}-$ level RH and wind fields, respectively, but the shading is the $200 \mathrm{hPa} \mathrm{T}$ 


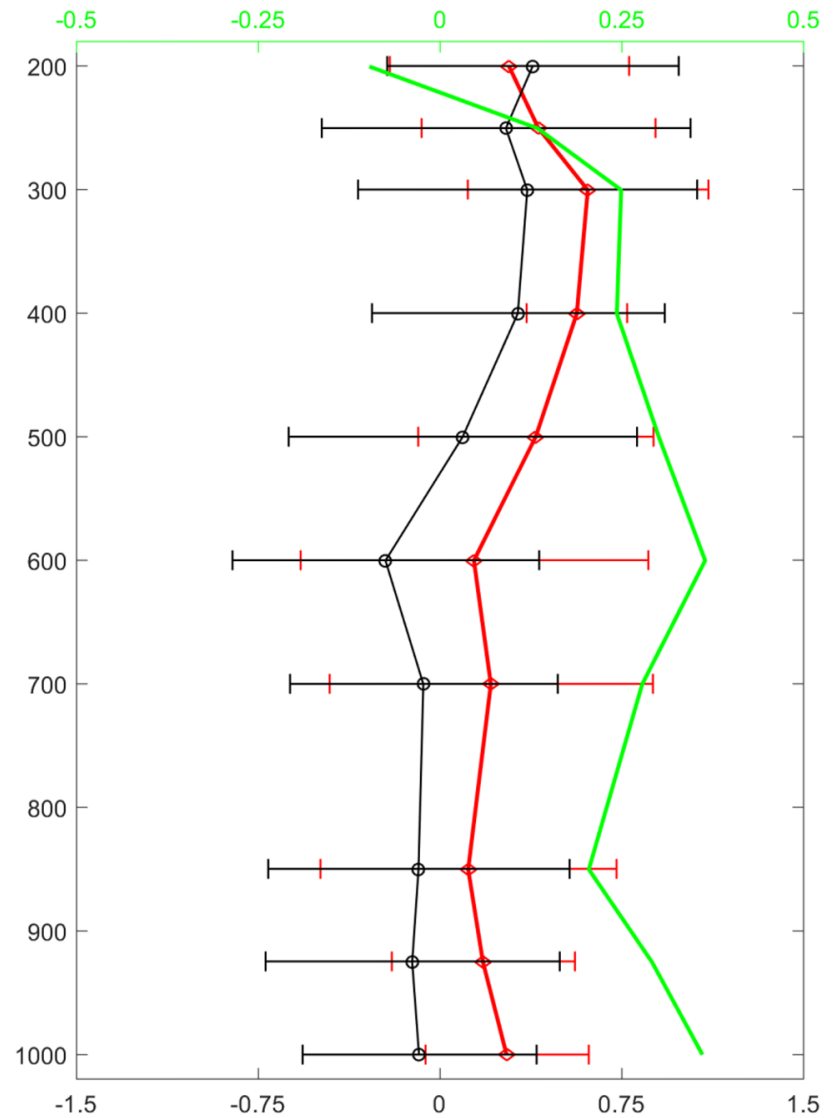

Fig. 2 Composites of the profiles of the 15-day low-pass-filtered temperature, standard error and difference between the SC and TC cases (unit: ${ }^{\circ} \mathrm{C}$ ). The red line is the average temperature in the $10^{\circ} \times 10^{\circ}$ box around the SC centers, the red stem is the standard error, the black line and stem are for TC cases, and the green line is the temperature difference between the SC and TC cases

\section{Air-sea factors impacting the difference in SC formation rate between the Pre- and Post-MS}

The SC formation rates during the Pre- and Post-MS were very different (close to 4 times larger in the Pre-MS than in the Post-MS). Moreover, in the BoB, the Pre- and Post-MS $\mathrm{SC}$ formation rates reached the global maximum and minimum, respectively (Table 1). We conducted a quantitative diagnosis of the $\mathrm{V}_{\mathrm{pot}}{ }^{2}$ term to understand the reason for the considerable difference in SC formation rates between the Pre- and Post-MS since $\mathrm{V}_{\text {pot }}{ }^{2}$ was able to effectively mirror the maximum TC PI (Bister and Emanuel 2002). Moreover, the BDI of $\mathrm{V}_{\text {pot }}^{2}$ was large (approximately 1.33), and the difference in this term between the Pre- and Post-MS exceeded the 99\% significance level (Table 4). The BDI and T-test results also supported the selection of $\mathrm{V}_{\text {pot }}{ }^{2}$ for quantitative diagnosis.

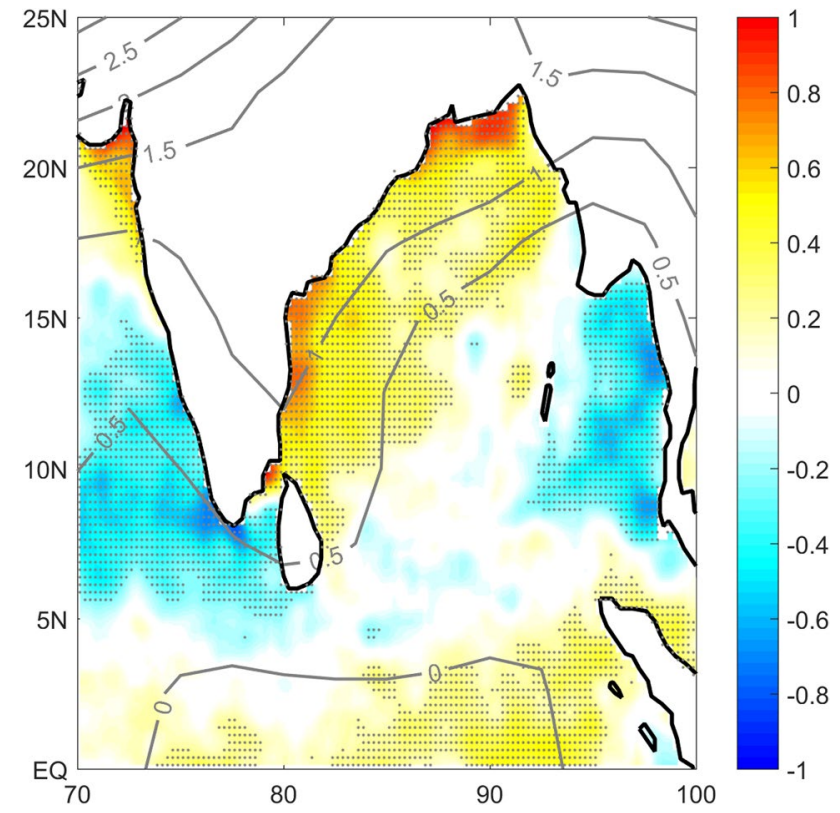

Fig. 3 Composite of the SST difference (shading, unit: ${ }^{\circ} \mathrm{C}$ ) and $1000 \mathrm{hPa}-$ level $\mathrm{T}$ difference (contour line, unit: ${ }^{\circ} \mathrm{C}$ ) between the $\mathrm{SC}$ and TC groups. The gray dots indicate that the SST difference significance level exceeds $95 \%$

Table 4 BDI and significance level of $\mathrm{V}_{\text {pot }}^{2}$ and its components between the Pre- and Post-MS

\begin{tabular}{lllll}
\hline Pre-Post $10^{\circ} \times 10^{\circ}$ & $\mathrm{V}_{\mathrm{pot}}{ }^{2}$ & $\mathrm{~T}_{\mathrm{vd}}$ & $\mathrm{T}_{\mathrm{vr}}$ & $\mathrm{T}_{\text {ed }}$ \\
\hline BDI & 1.33 & 0.72 & 0.45 & 1.39 \\
Significance & $>99 \%$ & $>99 \%$ & $>99 \%$ & $>99 \%$ \\
\hline
\end{tabular}

\section{1 $\mathrm{V}_{\text {pot }}^{2}$ analysis}

First, previous researchers have postulated that T, particularly the VTD between the lower and upper levels, plays the most important role in modulating whether TCs develop into SCs during the Pre- and Post-MS (Li et al. 2019a). Second, the TC intensity is affected mainly by $\mathrm{T}$ and water vapor according to the PI formula. Based on these two reasons, we naturally concluded that $\mathrm{T}$ was a key factor in modulating the SC formation rate difference between the Pre- and Post-MS.

We compared the 15-day low-pass-filtered $\mathrm{V}_{\text {pot }}{ }^{2}$ and $\mathrm{V}_{\mathrm{pot}}{ }^{2}$ calculated via the 15-day low-pass-filtered $\mathrm{T}_{\mathrm{vd}}, \mathrm{T}_{\mathrm{vr}}$ and $\mathrm{T}_{\text {ed }}$ to estimate the stability of the quantitative diagnosis. There were significant differences in the filtered $\mathrm{V}_{\text {pot }}{ }^{2}$ terms between the Pre- and Post-MS, and these significant differences established preconditions for the quantitative diagnosis. Furthermore, the $\mathrm{V}_{\text {pot }}{ }^{2}$ calculated via the filtered $\mathrm{T}_{\mathrm{vd}}, \mathrm{T}_{\mathrm{vr}}$, and $\mathrm{T}_{\mathrm{ed}}$ was in the region of the directly filtered $\mathrm{V}_{\text {pot }}{ }^{2}$. To some extent, this finding showed that the nonlinear 
effect was limited in the $\mathrm{V}_{\text {pot }}{ }^{2}$ calculation; thus, the diagnosis results should be robust (Fig. 4).

The BDI value and T-test results also confirmed that $\mathrm{V}_{\text {pot }}^{2}, \mathrm{~T}_{\mathrm{vd}}, \mathrm{T}_{\mathrm{vr}}$, and $\mathrm{T}_{\text {ed }}$ were significantly different between the Pre- and Post-MS, and all of them had a significance level greater than $99 \%$ (Table 4). The BDI values of $\mathrm{T}_{\mathrm{vd}}, \mathrm{T}_{\mathrm{vr}}$, and $\mathrm{T}_{\text {ed }}$ were $0.72,0.45$, and 1.39 , respectively. We could thus sort the possible effects of $\mathrm{T}_{\mathrm{vd}}, \mathrm{T}_{\mathrm{vr}}$, and $\mathrm{T}_{\text {ed }}$ on the TC PI by the BDI values (Table 4).

The total differentiation method (Li et al. 2013, 2019b; $\mathrm{Hu}$ et al. 2017) was utilized herein to quantitatively diagnose the relative contribution of each term to the $\mathrm{V}_{\text {pot }}^{2}$ difference to definitively ascertain the main factors and physical processes modulating the TC intensity difference between

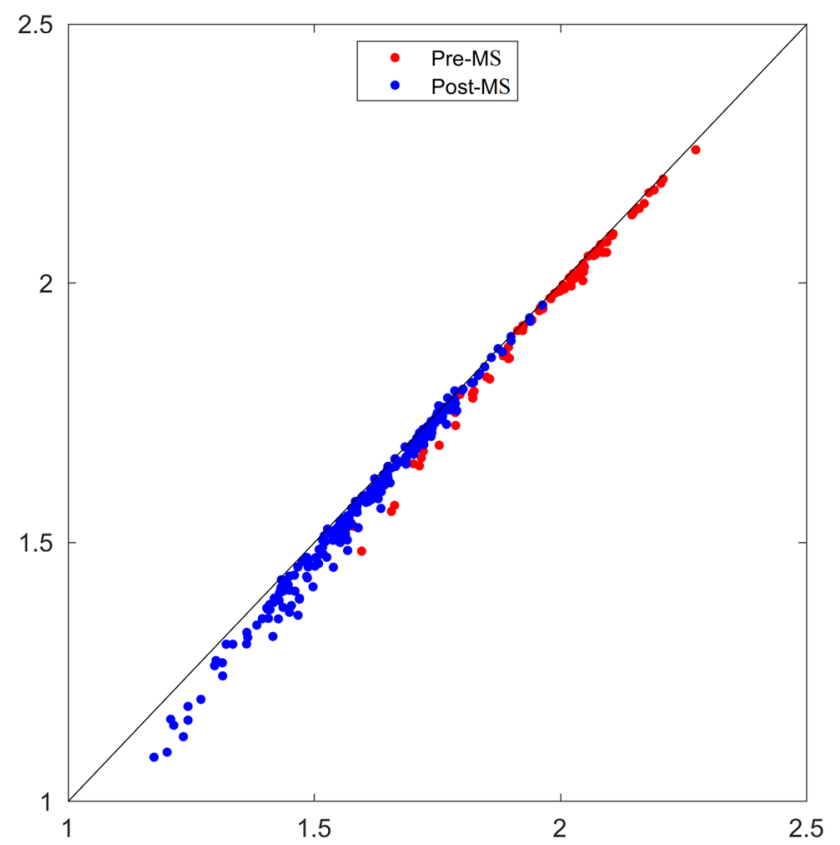

Fig. 4 Fifteen-day low-pass-filtered PI in a $10^{\circ} \times 10^{\circ}$ box around TC centers during the TC lifetimes in the Pre- and Post-MS over the $\mathrm{BoB}$. The $\mathrm{x}$-axis PI is calculated by the 15-day low-pass-filtered $\mathrm{T}_{\mathrm{vd}}$, $\mathrm{T}_{\mathrm{vr}}$ and $\mathrm{T}_{\text {ed }}$. The $\mathrm{y}$-axis PI is the 15-day low-pass-filtered PI the Pre- and Post-MS. The quantitative diagnosis results for $\mathrm{V}_{\text {pot }}{ }^{2}$ showed that $\mathrm{T}_{\text {ed }}$ played the most crucial role, with a contribution of $95.7 \%$, whereas $\mathrm{T}_{\mathrm{vd}}$ provided the secondhighest positive contribution, approximately $3.6 \%$, and $\mathrm{T}_{\mathrm{vr}}$ had a small contribution of approximately $0.7 \%$ (Table 5). These results were consistent with the BDI analysis.

The above results manifest that the significant difference in PI between the Pre- and Post-MS is determined mainly by the difference in $\mathrm{T}_{\text {ed }}$, which is composed of the bottom-level $(1000 \mathrm{hPa}-$ level) saturation equivalent potential temperature $\left(\theta_{\mathrm{e}}{ }^{*}\right)$ and boundary layer $(850 \mathrm{hPa}$-level) equivalent potential temperature $\left(\theta_{\mathrm{e}}\right)$. Here, the $\Delta \ln \theta_{\mathrm{e}}{ }_{\mathrm{e}}$ term is the primary factor modulating the $\Delta\left(\ln \theta_{\mathrm{e}}{ }^{*}-\ln \theta_{\mathrm{e}}\right)$ term (Table 5). The following research further diagnoses which environmental factors control the difference in $\theta_{\mathrm{e}}{ }^{*}$.

The saturation equivalent potential temperature is a function of both $\mathrm{T}$ and $\mathrm{q}_{\mathrm{s}}$ at the bottom level (1000 hPa level). When the bottom-level temperature $\left(\mathrm{T}_{\mathrm{s}}\right)$ in the Post-MS takes the place of the $\mathrm{T}_{\mathrm{s}}$ in the Pre-MS, the $\theta_{\mathrm{e}}{ }^{*}$ difference is approximately 0.009 , and the $\theta_{\mathrm{e}}{ }^{*}$ difference is approximately 0.013 when the $\mathrm{q}_{\mathrm{s}}$ in the Post-MS is employed instead of the $\mathrm{q}_{\mathrm{s}}$ in the Pre-MS. The relative contributions of the differences in $\mathrm{T}_{\mathrm{s}}$ and $\mathrm{q}_{\mathrm{s}}$ are $41 \%$ and $59 \%$, respectively. These results show that the differences in $\mathrm{T}_{\mathrm{s}}$ and $\mathrm{q}_{\mathrm{S}}$ play almost similar roles and cooperate to eventually cause a significant difference in the SC formation rate between the Pre- and Post-MS (Table 5). Furthermore, $\mathrm{q}_{\mathrm{s}}$ is largely modulated by $\mathrm{T}_{\mathrm{s}}$.

\subsection{The most impactful environment factors}

Figure 5 shows that the composite background SST around TC centers was warmer in the Pre-MS than the Post-MS with a difference of approximately $1.5^{\circ} \mathrm{C}$, which exceeded the 99\% significance level, and the BDI value based on the SST difference was 1.18. Similar to the SST characteristics, the composite of the $1000 \mathrm{hPa}$ background T around TC centers was far higher in the Pre-MS than the Post-MS (Fig. 5), and the temperature difference in the TC center area between

Table 5 Relative contributions of the changes in various terms to $\Delta$ Vpot2. The dominant terms are labeled with the symbol (bold values, a)

\begin{tabular}{|c|c|c|c|c|c|}
\hline Pre-Post & $\Delta \mathrm{V}_{\text {pot }}^{2}$ & SUM & $\alpha_{1} \bullet \Delta\left(\mathrm{T}_{\mathrm{s}}-\mathrm{T}_{0}\right)$ & $\alpha_{2} \bullet \Delta\left(\mathrm{T}_{\mathrm{s}} / \mathrm{T}_{0}\right)$ & $\alpha_{3} \cdot \Delta\left(\ln \theta_{\mathrm{e}}^{*}-\ln \theta_{\mathrm{e}}\right)$ \\
\hline & \multirow[t]{2}{*}{1.40} & \multirow[t]{2}{*}{1.38} & 0.05 & 0.01 & $1.32^{\mathrm{a}}$ \\
\hline & & & $3.6 \%$ & $0.7 \%$ & $95.7 \%$ \\
\hline & $\Delta\left(\ln \theta_{\mathrm{e}}^{*}-\ln \theta_{\mathrm{e}}\right)$ & SUM & $\Delta \ln \theta_{\mathrm{e}}^{*}$ & $-\Delta \ln \theta_{\mathrm{e}}$ & \\
\hline & \multirow[t]{2}{*}{0.016} & \multirow[t]{2}{*}{0.016} & $0.022^{\mathrm{a}}$ & -0.006 & \\
\hline & & & $138 \%$ & $-38 \%$ & \\
\hline & $\Delta \ln \theta_{\mathrm{e}}^{*}$ & SUM & $\Delta \mathrm{T}_{\mathrm{s}}$ & $\Delta \mathrm{q}_{\mathrm{s}}$ & \\
\hline & \multirow[t]{2}{*}{0.022} & \multirow[t]{2}{*}{0.022} & $0.009^{a}$ & $0.013^{a}$ & \\
\hline & & & $41 \%$ & & \\
\hline
\end{tabular}



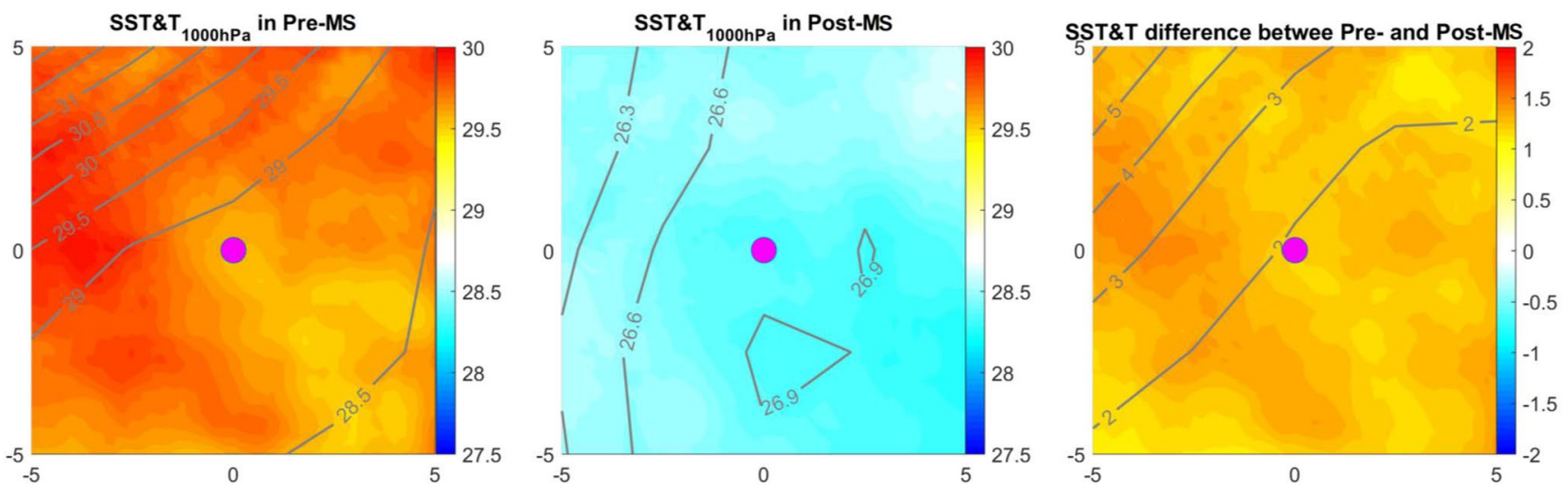

Fig. 5 Composites of the SST (shading, unit: ${ }^{\circ} \mathrm{C}$ ) and $1000 \mathrm{hPa}$-level $\mathrm{T}$ (contour line, unit: ${ }^{\circ} \mathrm{C}$ ) around the TC centers during the Pre-MS (left panel) and Post-MS (middle panel) and their difference (right panel) on a timescale greater than 15 days. The magenta dot is the TC center

Table 6 BDI and significance level of factors between the Pre- and Post-MS

\begin{tabular}{|c|c|c|c|c|}
\hline Pre-Post $10^{\circ} \times 10^{\circ}$ & $1000 \mathrm{hPa} \mathrm{SH}$ & $1000 \mathrm{hPa} \mathrm{T}$ & SST & $\begin{array}{l}\text { Bound- } \\
\text { ary layer } \\
\text { vorticity }\end{array}$ \\
\hline BDI & 0.72 & 1.54 & 1.18 & 0.29 \\
\hline Significance & $>99 \%$ & $>99 \%$ & $>99 \%$ & $>99 \%$ \\
\hline
\end{tabular}

the Pre- and Post-MS exceeded the $99 \%$ significance level (Table 6). Here, we postulate that the $\mathrm{T}$ difference between the Pre- and Post-MS was forced by the SST difference. The SST difference might be closely related to the annual cycle of SST in the BoB. According to the SST climatology in the BoB, the SST has two peak seasons: Pre-MS and Post-MS (Fig. 6). The BoB SST reached its annual climax in the PreMS and hence was higher in the Pre-MS than the Post-MS due to a shallower ocean mixing layer in the former period, which increased heating efficiency (Liu et al. 2013). All of these factors could help us to better understand the impact of the low-level $\mathrm{T}$ difference on the distinct difference of SC formation rates between the Pre- and Post-MS.
The bottom-level $\mathrm{q}_{\mathrm{s}}$ is another important factor modulating the TC intensity difference between the Pre- and PostMS. The saturated vapor pressure $\left(e_{s}\right)$ is a function of $T$, and a higher $\mathrm{T}$ produces a larger $\mathrm{e}_{\mathrm{s}}$ according to the Tetens formula. Moreover, $\mathrm{q}_{\mathrm{s}}$ is proportional to the quotient of $\mathrm{e}_{\mathrm{s}}$ and air pressure $\left(\mathrm{q}_{\mathrm{s}}=0.622 \mathrm{e}_{\mathrm{s}} / \mathrm{P}\right)$. Let us take the $1000 \mathrm{hPa}$ level as an example. $\mathrm{e}_{\mathrm{s}}$ is higher in the Pre-MS than the Post-MS because of the warmer $\mathrm{T}$ around TC centers in the former period. Larger values of $\mathrm{e}_{\mathrm{s}}$ would induce larger values of $\mathrm{q}_{\mathrm{s}}$, which means that the atmosphere would be able to contain more water vapor.

The higher T in the Pre-MS may bring more water vapor in the Pre-MS because the higher T might enhance evaporation resulting in more water vapor. Furthermore, a tropical convergence zone (TCZ) produced by wind shear close to zero (Akter and Tsuboki 2014) moves from south to north of the BoB, which is associated with the gradual establishment of the summer monsoon during the Pre-MS (Wang and LinHo 2002). This TCZ may result in the northward transport of water vapor to the vast area of the central BoB. In contrast, the southward movement of TCZ in the PostMS may bring less water vapor. The two conditions of high

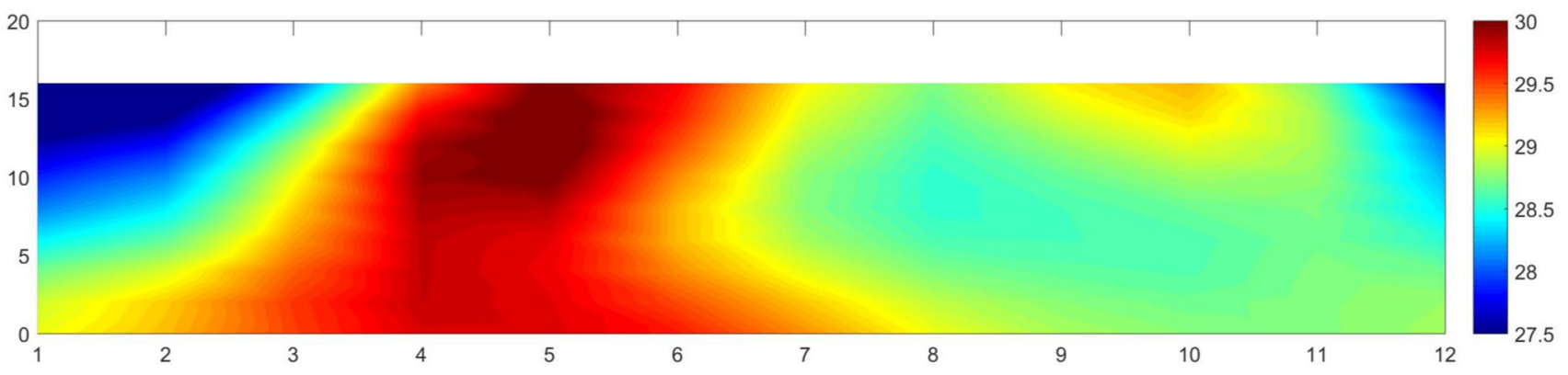

Fig. 6 Climatological annual cycle of the SST (unit: ${ }^{\circ} \mathrm{C}$ ) over the BoB. Shading shows the SST averaged between $85^{\circ}$ and $95^{\circ} \mathrm{E}$. The $\mathrm{y}$-axis is the latitude, and the $\mathrm{x}$-axis denotes the month 
$\mathrm{T}$ and TCZ movement cause the SH to approach $\mathrm{q}_{\mathrm{s}}$ at the $1000 \mathrm{hPa}$ level and make PI greatly present the intensity of TC over the BoB, which is the basis for using PI diagnosis to analyze the causes of the difference in SC formation rates between the Pre- and Post-MS. Figure 7 shows that the $1000 \mathrm{hPa}$ level $\mathrm{SH}$ around TC centers is far larger in the Pre-MS than the Post-MS. The BDI values of SH and the T-test results reconfirm a significant difference in $\mathrm{SH}$ at the low level between the Pre-MS and Post-MS TC groups (Table 6). The larger $\mathrm{q}_{\mathrm{s}}$ or $\mathrm{SH}$ at the $1000 \mathrm{hPa}$ level may result in a higher saturation equivalent potential temperature, reducing the atmosphere stability. The unstable atmosphere is conducive to the development of a convective system, which then promotes cyclone intensity enhancement. Eventually, the differences of $\mathrm{T}$ and $\mathrm{q}_{\mathrm{s}} / \mathrm{SH}$ at bottom level greatly contribute to the difference in $\mathrm{SC}$ formation rates between the Pre- and Post-MS in the BoB.

In addition, Fig. 8 displays the composites of vorticity around TC centers during the Pre- and Post-MS (Fig. 8, left and middle panel) and their difference between the two seasons (Fig. 8, right panel). The cyclonic background circulation promotes TC genesis in both seasons, and the cyclonic anomaly between the Pre- and Post-MS may be helpful for enhancing the TC intensity in the Pre-MS (Fig. 8). Finally, the VWS, a key factor impacting TC development, was similar between the Pre- and Post-MS, and therefore, its effect might be neglected (Fig. 9).

\section{Summary and conclusion}

According to the statistical analysis, there is a unique phenomenon in which the $\mathrm{SC}$ formation rates in the $\mathrm{BoB}$ reach the global maximum and minimum during the Pre- and PostMS, respectively. To confirm the causes of the significant difference in SC formation rates between the Pre- and Post$\mathrm{MS}$ in the BoB, we performed research involving the BDI, statistics, quantitative diagnosis and mechanism analysis, and we obtained the following main conclusions:

1. Similar to that during the Pre-MS, SC formation is modulated mainly by the VTD during the Post-MS in
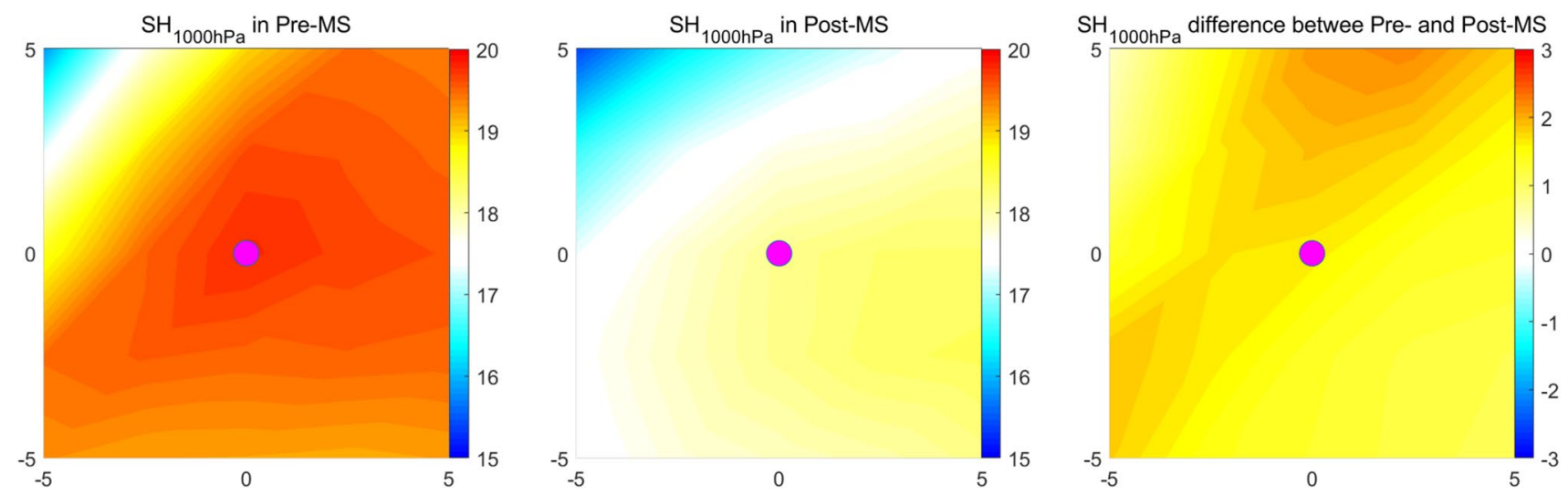

Fig. 7 Same as Fig. 5 but for SH (unit: $\mathrm{g} / \mathrm{kg}$ )
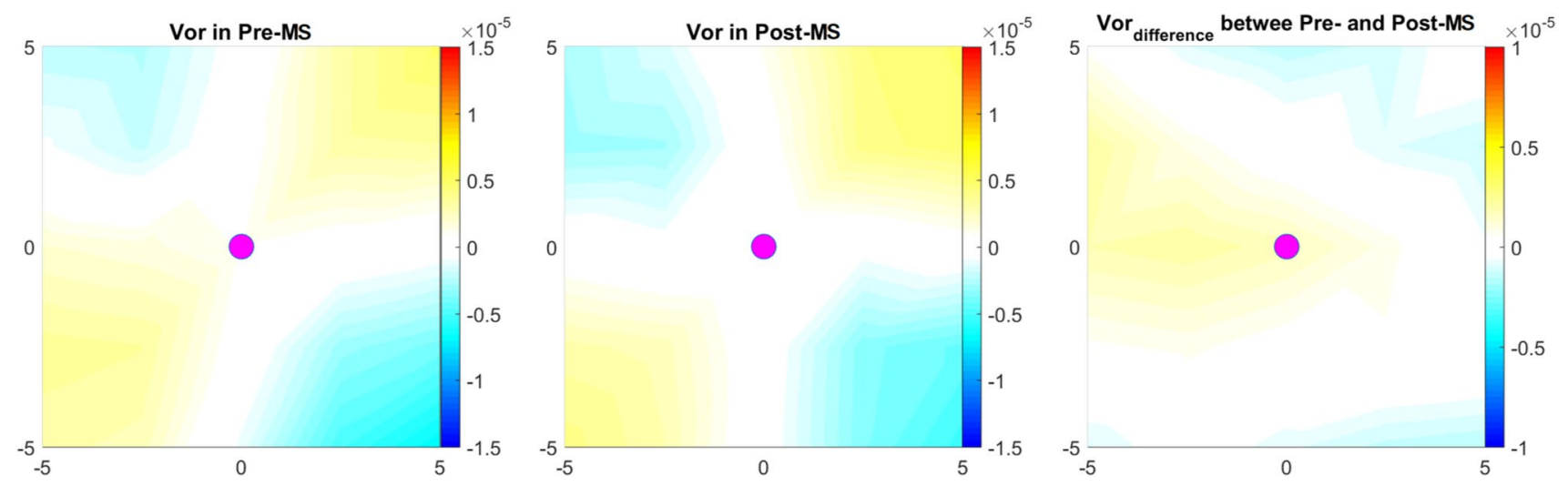

Fig. 8 Same as Fig. 5 but for the boundary-layer vorticity (unit: $\mathrm{s}^{-1}$ ) 

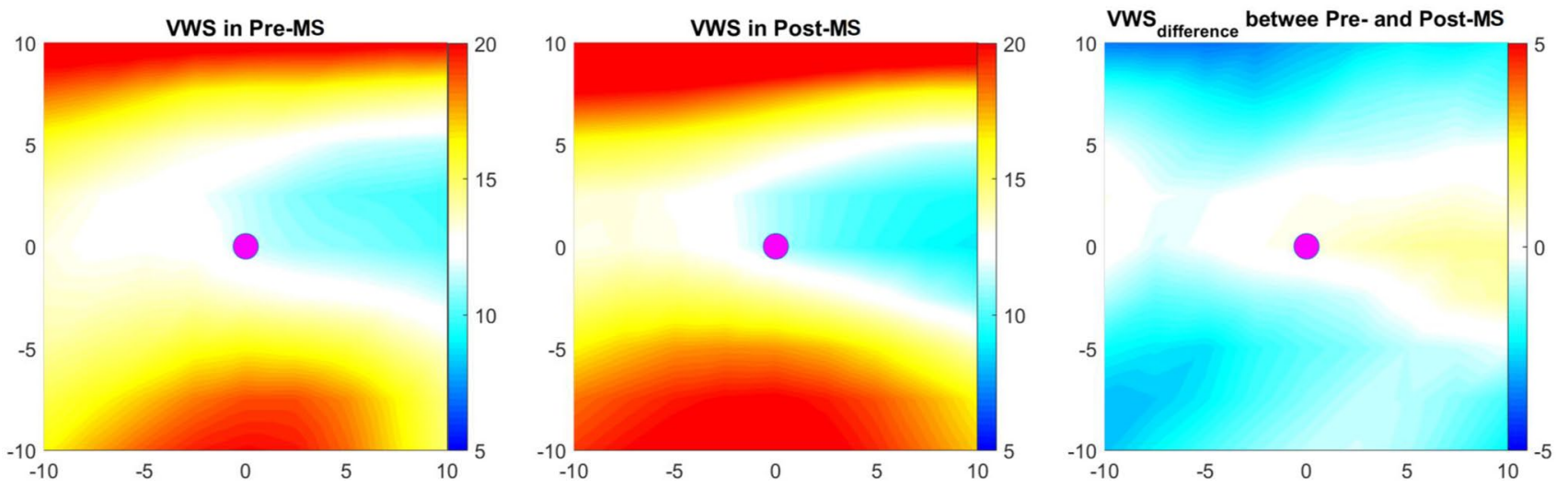

Fig. 9 Same as Fig. 5 but for VWS (unit: $\mathrm{ms}^{-1}$ )

the BoB. The significant difference in VTD between the $\mathrm{SC}$ and TC groups is principally due to the upper-level T variation during the Pre-MS. Conversely, unlike during the Pre-MS, the significant difference in VTD between the SC and TC groups is attributed chiefly to the lowlevel temperature difference during the Post-MS. The significant variation in VTD induces a difference in the PI of TC and eventually determines whether TCs can develop into SCs during the Post-MS in the BoB.

2. The statistical results show that the $\mathrm{V}_{\text {pot }}{ }^{2}$ term, which is able to effectively reflect the TC PI, is far larger in the Pre-MS than the Post-MS, with a significance level above $99 \%$. According to the quantitative diagnosis of $\mathrm{V}_{\text {pot }}{ }^{2}$, the remarkable difference in the $\mathrm{V}_{\text {pot }}{ }^{2}$ term is mainly due to the difference in the saturation equivalent potential temperature at the bottom level between the Pre- and Post-MS. Further diagnosis revealed that the difference in the saturation equivalent potential temperature originates from the $1000 \mathrm{hPa}$-level $\mathrm{T}$ and $\mathrm{q}_{\mathrm{s}}$, which provide similar contributions to the variation. Specifically, the bottom-level $\mathrm{T}$ difference is forced by the significantly different SST between the Pre- and Post-MS. The warmer bottom-level $\mathrm{T}$ results in a higher $\mathrm{e}_{\mathrm{s}}$, which means the atmosphere could contain more water vapor, and the warmer T may also enhance the evaporation and then cause more water vapor in the Pre-MS. Moreover, the gradually northward movement of TCZ may run a northward transport of water vapor to the central $\mathrm{BoB}$ in the Pre-MS. All of these conditions jointly produce a bottom-level SH that is close to $\mathrm{q}_{\mathrm{s}}$. That's also what makes PI well characterize the intensity of TC, which ensure robust results of PI diagnosis. Thus, the SST difference causes the variations of the bottom-level $\mathrm{T}$ and $\mathrm{q}_{\mathrm{s}}$ and ultimately results in the significantly different SC formation rates between the Pre- and Post-MS in the BoB.
It is worth noting that the study focuses on the period from TC generation to its maximum intensity, which indicates that the premise of the study is that TC had formed. The background-filed low- and upper-level $\mathrm{T}$ and $\mathrm{SH}$ around TC centers mainly modulate the difference in TC PI rather than the difference in TC frequency between the Pre- and Post-MS. The quantitative analysis based on the TC GPI (Emanuel and Nolan 2004) shows that the TC frequency difference between the Pre- and Post-MS is mainly due to the difference in the mid-level RH over the $\mathrm{BoB}(\mathrm{Li}$ et al. 2013).

The upper ocean, as the underlying surface of TC activities, plays an important role in TC genesis and development. The difference in SST makes a leading effort to introduce different SC formation rates between the Preand Post-MS in this study. We should obtain similar conclusions if we adopt the heat content of the upper ocean layer, which takes the place of the SST.

Finally, under the background of global climate warming, both oceanic and atmospheric factors are undergoing novel changes. Accordingly, the formation of SCs during the Pre- and Post-MS will also change at multidecadal and even longer timescales over the BoB. These changes and their inner mechanism must be investigated in more detail.

Acknowledgements The authors thank JTWC, NCEP/NCAR, ECMWF, and NOAA for the use of the datasets employed herein. This study is sponsored by the Marine S\&T Fund of Shandong Province for Pilot National Laboratory for Marine Science and Technology (Qingdao) (2018SDKJ0105-3), the Laboratory for Regional Oceanography and Numerical Modeling, the Pilot National Laboratory for Marine Science and Technology (Qingdao) (2019A04), the National Natural Science Foundation of China (NSFC) Grant 41406030, the China Scholarship Council, and the SEAGOOS-MOMSEI project of WEST-PAC/IOC.

Open Access This article is licensed under a Creative Commons Attribution 4.0 International License, which permits use, sharing, 
adaptation, distribution and reproduction in any medium or format, as long as you give appropriate credit to the original author(s) and the source, provide a link to the Creative Commons licence, and indicate if changes were made. The images or other third party material in this article are included in the article's Creative Commons licence, unless indicated otherwise in a credit line to the material. If material is not included in the article's Creative Commons licence and your intended use is not permitted by statutory regulation or exceeds the permitted use, you will need to obtain permission directly from the copyright holder. To view a copy of this licence, visit http://creativecommons. org/licenses/by/4.0/.

\section{References}

Akter N, Tsuboki K (2014) Role of synoptic scale forcing in cyclogenesis over the Bay of Bengal. Clim Dyn 43:2651-2662

Balaguru K, Chang P, Saravanan R, Leung LR, Xu Z, Li M, Hsieh JS (2012) Ocean barrier layers' effect on tropical cyclone intensification. PNAS 109(36):14343-14347. https://doi.org/10.1073/pnas. 1201364109

Bister M, Emanuel KA (2002) Low frequency variability of tropical cyclone potential intensity, 1 , Interannual to interdecadel variability. J Geophys Res 107:4801. https://doi.org/10.1029/2001JD000776

Blake ES, Landsea CW, Gibney EJ (2011) The deadliest, costliest, and most intense United States tropical cyclones from 1851 to 2010 (and other Frequently Requested Hurricane Facts). NOAA Technical Memorandum NWS NHC-6. Miami, FL: National Oceanic and Atmospheric Administration, National Weather Service, National Hurricane Center

Camargo SJ, Emanuel KA, Sobel AH (2007) Use of a genesis potential index to diagnose ENSO effects on tropical cyclone genesis. J Clim 20:4819-4834

Emanuel KA (2003) Tropical cyclones. Annu Rev Earth Planet Sci 31:75-104

Emanuel KA, Nolan DS (2004) Tropical cyclone activity and the global climate system. In: 26th Conference on hurricanes and tropical meteorology, Miami, FL, vol 10. American Meteorological Society A, Boston (Preprints)

Evan AT, Camargo SJ (2011) Aclimatology of Arabian Sea cyclonic storms. J Clim 24:140-158

Fu B, Peng SM, Li T, Stevens D (2012) Developing versus nondeveloping disturbances for tropical cyclone formation, part II: western North Pacific. Mon Weather Rev 140(4):1067-1080

Gray WM (1968) Global view of the origin of tropical disturbances and storms. Mon Wea Rev 96:669-700

Gray WM (1979) Hurricanes: their formation, structure and likely role in the general circulation. Meteorology over the Tropical Oceans, In: Shaw DB (Ed.). Royal Meteorological Society, 155-218

Hamming RW (1989) Digital filters. Prentice-Hall, Englewood Cliffs

Hu F, Li T, Liu J, Peng M (2017) Cause of interdecadal change of tropical cyclone controlling parameter in the Western North Pacific. Climate Dyn 51:719-732. https://doi.org/10.1007/s00382-017-3951-z

Jakobsen F, Azam MH (2006) Cyclone storm surge levels along the Bangladeshi coastline in 1876 and 1960-2000. Coast Eng J 48(3):295-307

Kikuchi K, Fudeyasu H (2009) Genesis of tropical cyclone Nargis revealed by multiple satellite observations. Geophys Res Lett 36:L06811. https://doi.org/10.1029/2009GL037296

Kotal SD, Bhowmik SK, Kundu PK, Das AK (2008) A statistical cyclone intensity prediction (SCIP) model for the Bay of Bengal. J Earth Syst Sci 117(2):157-168

Kotal SD, Kundu PK, Bhowmik SK (2009a) An analysis of sea surface temperature and maximum potential intensity of tropical cyclones over the Bay of Bengal between 1981 and 2000. Meteor Appl 16:169-177
Kotal SD, Kundu PK, Bhowmik SK (2009b) Analysis of cyclogenesis parameter for developing and nondeveloping low-pressure systems over the Indian Sea. Nat Hazards 50:389-402

Li Z, Yu WD, Li T, Murty VSN, Tangang F (2013) Bimodal character of cyclone climatology in Bay of Bengal modulated by monsoon seasonal cycle. J Clim 26:1033-1046

Li K, Li Z, Yang Y, Xiang B, Liu Y, Yu W (2016) Strong modulations on the Bay of Bengal monsoon onset vortex by the first northward-propagating intra-seasonal oscillation. Climate Dyn 47(1-2):107-115

Li Z, Li T, Yu WD (2019a) Environmental conditions regulating the formation of super tropical cyclone during pre-monsoon transition period over Bay of Bengal. Climate Dyn 52:3857-3867

Li Z, Yu WD, Li KP, Wang HW, Liu YL (2019b) Environmental conditions modulating tropical cyclone formation over the Bay of Bengal during the Pre-Monsoon Transition Period. J Clim 32:4387-4394

Lin II, Chen CH, Pun IF, Liu WT, Wu CC (2009) Warm ocean anomaly, air sea fluxes, and the rapid intensification of Tropical Cyclone Nargis (2008). Geophys Res Lett 36:L03817. https://doi.org/10.1029/ 2008GL035815

Liu Y, Yu WD, Li KP (2013) Heat budget for the double peak of SST seasonal cycle in the Bay of Bengal. Adv Marine Sci 31(4):429-437

McPhaden MJ et al (2009) Ocean-atmosphere interactions during Cyclone Nargis. Eos Trans Amer Geophys Union 90:53. https:// doi.org/10.1029/2009EO070001

Needham HF, Keim BD, Sathiaraj D (2015) A review of tropical cyclonegenerated storm surges: global data sources, observations, and impacts. Rev Geophys 53:545-591. https://doi.org/10.1002/2014R G000477

Neetu S, Lengaigne M, Vialard J (2019) Pre/post-monsoon Bay of Bengal Tropical Cyclones intensity: role of air-sea coupling and large-scale background state. Geophys Res Lett. https://doi.org/10.1029/2018G L081132

Peng SM, Fu B, Li T, Stevens DE (2012) Developing versus nondeveloping disturbances for tropical cyclone formation. Part I: North Atlantic. Mon Weather Rev 140(4):1047-1066

Pielke RA Jr, Gratz J, Landsea CW, Collins D, Saunders MA, Musulin R (2008) Normalized hurricane damage in the United States: 1900-2005. Nat Hazards Rev. https://doi.org/10.1061/(ASCE)15276988(2008)9:1(29)

Rao VB, Camila CF, Franchito SH, Ramakrishna SSVS (2008) In a changing climate weakening tropical easterly jet induces more violent tropical storms over the north Indian Ocean. Geophys Res Lett 35(15):L15710. https://doi.org/10.1029/2008GL034729

Thadathil P, Muraleedharan PM, Rao RR, Somayajulu YK, Reddy GV, Revichandran C (2007) Observed seasonal variability of barrier layer in the Bay of Bengal. J Geophys Res 112:C02009. https://doi. org/10.1029/2006JC003651

Vissa NK, Satyanarayana ANV, Prasad Kumar B (2013) Comparison of mixed layer depth and barrier layer thickness for the Indian Ocean using two different climatologies. Int J Climatol 33:2855-2870

Wang B, LinHo (2002) Rainy season of the Asian-Pacific summer monsoon. J Climate 15:386-398

Webster PJ (2008) Myanmar's deadly daffodil. Nat Geosci 1:488-490. https://doi.org/10.1038/ngeo257

Yanase W, Taniguchi H, Satoh M (2010) The genesis of tropical cyclone Nargis (2008): environmental modulation and numerical predictability. J Meteor Soc Japan 88:497-519

Yanase W, Satoh M, Taniguchi H, Fujinami H (2012) Seasonal and intraseasonal modulation of tropical cyclogenesis environment over the Bay of Bengal during the extended summer monsoon. J Clim 25:2914-2930

Yesubabu V, Kattamanchi VK, Vissa NK, Dasari HP, Sarangam VBR (2020) Impact of ocean mixed-layer depth initialization on the simulation of tropical cyclones over the Bay of Bengal using the WRF-ARW model. Meteorol Appl 27:e1862. https://doi.org/10. 1002/met. 1862 
Zhang M, Zhou L, Chen D, Wang C (2016) A genesis potential index for Western North Pacific tropical cyclones by using oceanic parameters. J Geophys Res Oceans 121:7176-7191. https://doi.org/10. 1002/2016JC011851
Publisher's Note Springer Nature remains neutral with regard to jurisdictional claims in published maps and institutional affiliations. 